\title{
Irish Sea Coastal Stakeholder Engagement in NW England: consultation, participation, strategic purpose and rhetoric. Do you reap just what you sow?
}

\author{
RB Johnson, University of Central Lancashire rbjohnson@uclan.ac.uk \\ DrMClark, University of Central Lancashire mclark@uclan.ac.uk
}

\begin{abstract}
The creation of a holistic more inclusive approach to marine management could be positively influenced by the development of well structured and sincere Stakeholder Engagement and Public Participation (SEPP) processes. However poorly designed frameworks and processes lacking sincerity may engender scepticism, mistrust and create barriers in the attainment of a thriving and diverse coastal economy. During 2009 a public participation and stakeholder engagement policy has been used by government agencies, Defra and the Department of Energy and Climate Change to gauge public opinion within the marine and coastal environment of the Irish Sea. This concerns the development of Irish Sea Conservation Zones and the UK's Nuclear Newbuild programme. Both issues have complex dynamics regarding their environmental, economic, societal and sustainability aspects. This paper studies two contrasting styles of SEPP deployed during this critical 'first contact' stage by a participatory observation approach and assesses how this phase may affect the development of the engagement process and how this may affect a project's outcome.
\end{abstract}

\section{Keywords}

Stakeholder Engagement, Public Participation, Irish Sea Conservation Zones, Nuclear New Build, First contact, Holistic,

\section{Introduction}

The formation of the first coalition government in the United Kingdom (UK) has promised a new era of policy development. Although it purports to be the UK's greenest government to date, immediate priorities have been focused on reducing the fiscal deficit and incorporating or eliminating what are presented as unnecessary or ineffective commissions, QUANGO's and interventions. These include some with an environmental focus (Defra 2010).

In the document 'The Coalition our Programme for Government' the new administration outlines the aims of the Government (UK Cabinet Office, 2010) these were also addressed within the Queens speech which included a 'Decentralisation and Localism Bill' intended for use in England and Wales (Scotland and Northern Ireland have their own legislation), 'to devolve greater powers to councils and neighbourhoods and give local communities control over housing and planning decisions'. Benefits are sought through 'Empowering local people, freeing local government from central and regional control and giving local communities a real share in local growth.' and by achieving 'A more efficient and more local planning system.' Among the bill's main elements will be abolition of Regional Spatial Strategies (RSS) and of the Infrastructure Planning Commission (IPC). This is to be replaced by 'an efficient and democratically accountable system that provides a fast-track process for major 
infrastructure projects' and which gives 'residents the power to instigate local referendums on any local issue...' (UK, Prime Minister's Office, 2010a).

A number of the new Government's aims directly affect the development of the marine environment. Although none of these represent new thinking, challenges will arise during their implementation that may demand more open styles of engagement and improvement in information streams. The main aims for Energy and Climate Change are set out in terms of the Government's belief '...that climate change is one of the gravest threats we face, and that urgent action at home and abroad is required. We need to use a wide range of levers to cut carbon emissions, decarbonise the economy and support the creation of new green jobs and technologies, and implement a full programme of measures to fulfil our joint ambitions for a low carbon and eco-friendly economy'. Aims for Environment, Food and Rural Affairs (which interestingly do not include fishing) are expressed in terms of a belief that 'we need to protect the environment for future generations, make our economy more environmentally sustainable, and improve our quality of life and well-being', 'we also believe that much more needs to be done to support the farming industry, protect biodiversity and encourage sustainable food production.' (UK Cabinet Office, 2010)

With the current fiscal deficit there is a distinct possibility that government spending in many areas will be cut and increasingly requirements for Stakeholder Engagement and Public Participation (SEPP) will fall upon the commercial sector. As Hartmann and Campelo (1998) expounded, 'enforcement is passed on to user groups, mainly to make up the lack of funds and manpower of the responsible authority'. Referring to their work in the context of fisheries research in Brazil, Seixas (2004) reports 'that government consultation with civil society and the use of local knowledge in resource management depend largely on the government staff's own beliefs about the value of local knowledge and the potentials of community-based management and not so much on his/her organisation agenda'. In situations where officials are not obliged to take local expertise or interests into account they may be reluctant to value local knowledge or to permit co-management arrangements to take place.

\section{An Obligation to Consult}

Since the adoption of the Aarhus agreement (UNECE 1998), there is an onus on those submitting proposals to provide the conduit for effective public participation. The government, its agencies and public enterprise are required to grant the public rights regarding access to information, public participation and access to justice, in governmental decision-making processes on matters concerning the local, national and trans-boundary environment' The wording of the agreement is specific and demanding, for example:

\section{Article 5}

Collection and Dissemination of Environmental Information

1. Each Party shall ensure that:

Public authorities possess and update environmental information which is relevant to their functions; 
- Mandatory systems are established so that there is an adequate flow of information to public authorities about proposed and existing activities which may significantly affect the environment;

(UNECE 1998)

As this agreement has been in place for more than a decade it might be asked if the powers really exist to expose and punish sham forms of public participation, or to require authorities and operators to make available all the information necessary to provide proper safeguards, including denial of planning or operating permission, or closure, where plant fails to achieve or keep within set limits. A less sceptical view can look to the rolling out of consultation and public engagement and to an ongoing process that embeds the underlying principles behind Aarhus and subsequent conventions. A meeting in Kiev (UNECE 2003) identified the following as 'some of the main factors that may pose obstacles to implementation

- Economic: general lack of resources, high costs of specialised training.

- Political: lack of political will, negative pressure from interest groups, fledgling NGO community.

- Social/cultural: poor perception of environmental issues among the public, low level of awareness of environmental rights, public apathy.

An earlier meeting at Lucca in October 2002 committed Aarhus declaration signatories to creating partnerships for sustainable development: 'Only through building partnerships with and within a well-informed and empowered civil society, within the framework of good governance and respect for human rights can [the challenge of solving the major ecological problems of our time] be met.' (UNECE 2004)

In order to comply with the demands of the convention and the government's determination to push forward with the Marine Management Organisation (MMO) for England ( $\mathrm{MMO}$, DEFRA 2009, HM Government and the MMO 2010), for requirements to achieve renewable energy development in the marine environment and to work towards mitigation of climate change impacts. There will be an increase in processes that require good stakeholder engagement practices. This is now especially relevant as the need to include socio-economic considerations is included in many new legislative instruments e.g. Marine Planning and Marine Conservation Zones.

\section{Justification for Research}

The structure and delivery of the first contact phase of engagement may be instrumental in furthering the development of constructive collaboration and meaningful engagement. Porrit (2008) refers to "Social, Economic and Environmental Partners" as one of the lost elements of English Regional Assemblies, replaced by a more general obligation to consult 
stakeholders and by a haphazard and generally unsatisfactory mix of largely economic regional 'leadership' bodies. Though the principle of SEPP appears to be accepted as necessary, perhaps to meet Aarhus and related commitments, more pragmatically, it may be required to have such procedures in place for initiatives to be accepted, and for them to work effectively. During 2009 a Stakeholder Engagement and Public Participation (SEPP) policy was used by government agencies, Defra and the Department of Energy to gauge public opinion within the marine and coastal environment of the Irish Sea. These concern the development of Irish Sea Conservation Zones and proposals for siting new nuclear power facilities at (amongst others) Heysham in Lancashire and Millom in Cumbria.

To justify the requirement for increased SEPP it is important that the value of this type of engagement should be validated by both practitioners and respondents. To date there is little available evidence or published research to justify the claims of practitioners with regard to the outcomes of their work with stakeholders or the general public. Poorly designed processes may create negative, possibly intergenerational socio-economic effects. It is therefore necessary that all engagement activity should be equitable, fair and open. Are these criteria being met in current SEPP activities?

\section{Research Process}

The research on which this paper is based includes studies of two contrasting styles of SEPP deployed in the early phases of the Irish Sea participation processes. It adopts a participatory observation approach and assesses how this critical phase may affect the early development of an engagement processes. Both of the issues addressed have complex dynamics in terms of their potential for development of renewable energy resources within and on the periphery of the coastal zone of the Irish Sea. This paper analyses delivery style at two workshops undertaken by the ISCZ (Irish Sea marine conservation zone) project and two at the New Nuclear (NN) consultation in the North West of England. The four were chosen at random from a total of 16 SEEP workshops held in the region during late 2009 and early 2010.

Although this paper has been produced at a relatively early stage in the research project, and discusses the importance of the early contact phase of engagement processes, it is intended to form the backbone of future work studying the mechanics of engagement in further depth. The research builds on previous work carried out by Hickey and Mohan 2005 regarding problems of the system and the development of a best practice approach and Brown et al 2005 which stated that 'We recommend that the research approach be extended to other case study sites and coastal management issues and combined with analysis at the national/regional decision-making level. Further work at both these levels would provide a foundation for the development of institutional structures that can enhance cross-scale integration, long-term strategic planning across sectors, and local adaptive capacity'.

\section{Preliminary research findings}

It was interesting to see how small and sometimes seemingly insignificant details undertaken early on the day of each workshop set the tone for the day ahead. ISCZ workshops were less formal than those for NN and appeared at the outset to be less constructed. In fact there was a well thought out process being used, and as the day progressed a distinct pattern emerged that was consistent in both of the ICZM meetings attended. The NN debate was from the outset more controlled in its approach, time limits were strict and short and the format of the meetings changed between events. To take part, participants had been required 
to apply for tickets prior to both ISCZ and NN workshops. But the NN process gave the appearance that attendees may have been vetted and a number of participants commented on this. One suggested that it was 'a vetting process designed to control the response'. In informal but private conversation with some of the participants, a number agreed with this assessment of the event. This may not have been the intention of the organisers but this level of control had already seeded doubt in the minds of a number of persons.

The facilitators were sharply contrasted in their presentational style. The one at the NN workshops was dominant from the outset of the meeting. She was a power dresser, matching the style of her employers. This raised one comment from a participant who suggested 'she is one of them, see how she dresses'. The facilitator whilst trying to reassure the audience that this was their chance to comment freely on the NN process controlled the morning debate so that it really became a question and answer session with very little opportunity to develop the discussion. This was particularly prevalent at the Lancaster meeting. The facilitator at the ICZM meetings had a far more open approach and was dressed in a manner which was more in line with the majority of the audience - this was also the case for members of the ICZM team.

Time constraint was a major obstacle which inhibited the SEPP process. At the NN meetings only two hours were available. This was an inadequate period in which to discuss important issues, disseminate and gain information, and engage effectively with stakeholders and the public. It also creates negative feelings within the audience. 'This is not a real consultation it is only lip service' was one comment from the floor at NN Lancaster. ICZM meetings were much better in this regard as the workshop lasted a full day with a sensible break for lunch. This appeared to improve the productivity of both staff and participants, though the much longer time commitment required of participants raises other questions about public engagement. While many people may be able and willing to give up a couple of hours, a full day may put off or exclude many.

Attendees were greeted on entry to the ICZM event by key members of the team who were personable and chatty. Efficient participation was encouraged from an early stage, with comments being asked for at reception as well as at other times during the day. This contrasted sharply with the meeting of the NN, especially at Lancaster. The initial greeting was very muted and impersonal and the receptionist stamped each attendee hand with an ink stamp. This incensed a number of participants, especially the several of the older participants whom commented that 'I have never been treated like this, we are not cattle'. This set a very poor tone for the day especially for these participants.

It was surprising how muted the level of opposition to the NN proposals were, especially at the Lancaster meeting. Was this due to the level of control prior to and during the meeting or was this due to fact that the population of the Lancashire and Cumbrian coastline has been for many years involved in the development of the nuclear industry and are less emotional about its effects? There may also have been further subconscious control created by the fact that the audience were told that the meeting was being recorded from the outset and this certainly made some of the audience more self-conscious and muted in some of their responses. It is notable that most of the named individuals on the published transcript had a role in political or campaigning organisations, and that few comments were anonymous (Department of Energy \& Climate Change 2009b). There was also a large number of officials 
in the hall during the NN workshop which created an oppressive atmosphere in the hall and created unease within the audience who were to be seen glancing towards them.

The 'roadshow' exhibition that was open to the public on a few days before the event emphasized 'factual' and scientific aspects of the proposals under discussion. A New Nuclear website explained why the public should go to the exhibition:

'What is the purpose of the local exhibitions? These exhibitions will raise awareness of the consultation, encourage people to take part and allow them to discuss issues with senior policy officials. It is also an opportunity for the local community to comment on our assessment of the relevant nominated site. We want people who visit the exhibition to:

- Learn more about the draft Nuclear National Policy Statement and how a site in your area has been assessed as a potential location for a nuclear power station.

- Find out how you can have your say in the consultation process.

The exhibition will feature a series of interactive touch-screens and graphic panels giving information on the draft Nuclear National Policy Statement, the consultation process and the local site information.

'They will aim to introduce the draft Nuclear National Policy Statement and the Government's assessment of sites in an engaging, interactive and understandable way. Respondents will still need to read the consultation documents, however the exhibitions are intended to help summarise the detailed information contained in the draft National Policy Statement and help people engage with them. People will be able to wander in at their convenience and will not have to book. The exhibition will also provide access to the documentation submitted by the Government for review' (Department of Energy and Climate Change 2009a)

The exhibition reflected and presented evidence from a large amount of professional documentation available at the events, which emphasised environmental impacts, habitat damage and the social and economic implications of new nuclear development. This did little to explore or refute some of the more fundamental criticisms of nuclear energy, for example impacts associated with mining, fuel preparation, embodied carbon in the construction process and the excessively long lead time for reactor construction the possibility of containment failure. From the transcript of the Lancaster event, most of these concerns were raised during the consultation (Department of Energy \& Climate Change $2009 \mathrm{~b})$. It is arguable that few received satisfactory answers. There was good treatment of the risks of an energy gap and much mention of the threat of climate change, though the implications of anything other than a small resulting rise in sea level were neglected. The Northwest England and Wales Shoreline Management Plan (SMP) suggests (Appendix C) that this part of the UK experiences less than $0.5 \mathrm{~mm}$ sea level change a year, though long term trends (North West \& North Wales Coastal Group 2008) will see a rise of about ten metres by the year 9000AD, much less than implied by the Climate Change consultation for Lancashire which shows how much of the county would be lost by a 14 metre rise (Lancashire Climate Change Partnership 2008). In the shorter term, Lancaster New Nuclear exhibition showed that the proposed new reactor is sited well away from coastal tidal floodplain, and the more recent SMP consultation's overview is reassuring: 


\section{Why participate}

Why do stakeholders and public take part in engagement? From 20 semi structured interviews carried out after the ICZM workshops the following results were achieved:

$25 \%$ attended as part of their work in local or national government

$30 \%$ were members of the public concerned for the marine environment

$15 \%$ were working for NGOs

$20 \%$ were local fishermen or from fishing bodies

$10 \%$ were involved in leisure activities

Of this group $45 \%$ were concerned about some loss of amenity, business opportunity or restrictions on current use.

People attend from the commercial sector because they recognise a potential threat to their livelihood. A local fisherman who had had previous contact with the research group commented at the Blackpool ICZM meeting that he 'would give nothing away', another asked 'what should I tell them' and 'this isn't another Bass Consultation is it' comments which suggest they were threatened by the potential outcome of the consultation and that they had had poor contact before. Both were seen later in the day actively engaging in the discussion and drawing maps of local fishing grounds and areas which they recognised as important!

\section{Conclusion}

In the early stages of the group meetings both at ICZM and NN, many appeared unwilling to divulge information or to make comments. Ones that did were usually guarded or measured in their response; a very small minority was openly hostile to the proceedings early in the day. These were mainly regulated by other attendees on the floor who wished to participate in the day and learn more about the processes.

At the NN consultations people were concerned about damage to the environment loss of jobs, future shortages of energy, public health issues and lack of local infrastructure development. There was less argument than might have been expected at these meetings. Participants appeared to be generally pragmatic in their approach. Some of this effect could have been generated by the fact that Lancaster in particular has been in close proximity to and involved in the nuclear generation industry for many years. There was a more emotional debate at Millom as people generally argued against any development, a single baby in the hall appeared to have a great influence on both the panel and the audience and added an intergenerational dimension to a number of the comments.

The engagement processes and techniques used in the ISCZ and NN processes studied in this work contrasted in a number of ways. Some were small details which may have flowed from a single person's interaction with the wider group. Others were more mundane and could have been created by the choice of venue, the style of the presentations and the manner, behaviour and appearance of the facilitators. 
From the research a number of interesting points emerged:

- Facilitators and their assistants need to be trained and competent in their approach to workshop events. Levels of competency need to be correctly identified by the facilitator

- The appearance of the facilitators and staff may have a greater impact on the proceedings than is thought. Alignment in dress code with either side may create a feeling of allegiance to one group or the other, especially from the standpoint of the visitors on the floor

- Venues are important. The use of the town hall in Lancaster for the first NN meeting attended was oppressive with poor lighting and poor heating. Interestingly the level of heating reduced dramatically as the morning reached its conclusion, three people commented on this after the meeting. The openness of the Millom venue was better by using a local school participants were less inhibited.

- Greeting is critical. The team style at ICZM worked well and involved participants within minutes of registration this generated early results for the facilitation team and primed the participants that there was more to come. The more sullen approach of $\mathrm{NN}$ with little eye contact and the ink stamp entry pass upset a number of attendees from the very outset.

- Two hours is not long enough for an effective engagement process to be undertaken and only reinforces scepticism of the group. The confidence of the groups and subsequently the responses improve as the day passes, attendees began to open as they realized they weren't at risk and they were generally more willing to participate as the day progressed.

There will probably always be some often legitimate scepticism from stakeholders and by members of the public no matter how well an engagement process is undertaken. People governments and companies still dress up 'all variety of manipulations up as 'participation in the process', 'citizen consultation' and other shades of techno-bable' (Arnstein 1969). If some of the issues noted above are not seriously considered consultation risks being sham: a way of bullying through 'inevitable' change, of providing legitimacy to authoritarian intervention (Clark 1989, 1991) and perhaps of asserting 'expert' and 'scientific' knowledge, and corporate interests, over local understanding and ways of life. More importantly poor engagement and consultation may affect intergenerational prospects for good engagement and participation and impede development of holistic answers which could develop a fully rounded marine policy.

\section{References}

Arnstein, S. R., 1969 'A Ladder of Citizen Participation, Journal of the American Institute of Planners (JAIP) 35: 4, July 1969, pp. 216-224. At http://lithgow-schmidt.dk/sherryarnstein/ladder-of-citizen-participation.pdf or http://www.apho.org.uk/resource/item.aspx?RID=82367

Brown, K. et al., 2005, Responding to climate change: inclusive and integrated coastal analysis, Tyndall Centre Technical Report 24 (PDF, 103 pages 656kB) 
Christensen, S. M.,2008. Case study 5 - Wadden Sea National Park Pilot, Denmark. Scottish Natural Heritage Research, Annex to Commissioned Report No. 271 http://www.snh.org.uk/strategy/CMNP/sr-adnp01.asp

Clark, M., 1989 "EIA and the assessment of British Planning", in Herington, J. and Clark, M. EIA and the Planning Process, Mansell, London. pp 124-139.

Clark, M.,1991, 'Towards Criteria for Planning: Britain and the Spirit of EIA', Ch. 9 in Ashworth, G \& Kivell, P.T. (Eds.), Land, Water and Sky: European Environmental Planning, IBG/ Rijksuniversiteit Groningen.

Defra., 2009, Managing our marine resources: the Marine Management Organisation, PB 13201 http://www.defra.gov.uk/environment/marine/documents/legislation/mmo-brochure.pdf

Defra., 2010 'Defra announces changes to arm's length bodies', News Press Releases, 22 July, http://ww2.defra.gov.uk/2010/07/22/arms-length-bodies/

Department of Energy and Climate Change., 2009a, Consultation on Draft National Policy Statements for Energy Infrastructure

http://data.energynpsconsultation.decc.gov.uk/documents/aos/heysham/report.pdf

Department of Energy \& Climate Change., 2009b, Transcript. Heysham Public Consultation on New Nuclear Power Station 30 November http://data.energynpsconsultation.decc.gov.uk/documents/transcription heysham.pdf

Department of Energy \& Climate Change., 2009c, Appraisal of Sustainability: Site Report for Heysham EN-6: Draft National Policy Statement for Nuclear Power Generation, http://data.energynpsconsultation.decc.gov.uk/documents/aos/heysham/report.pdf

Evans, E., Ashley, R., Hall, J., Penning-Rowsell, E., Saul, A., Sayers, P., Thorne, C. \& Watkinson, A., 2004, Foresight. Future Flooding. Scientific Summary: Volume I - Future risks and their drivers. Office of Science and Technology, London.

Hartmann, W.D. and Campelo, C.M.F., 1998, 'Ambivalent enforcers. Rules and conflicts in the co-management of Brazilian reservoir fisheries.' Paper presented at the Seventh Conference of the International Association for the Study of Common Property - Crossing Boundaries. June, Vancouver, Canada.

HM Government and the MMO., 2010, MMO framework document, March, http://www.defra.gov.uk/environment/marine/documents/legislation/mmo-framework.pdf

Lancashire Climate Change Partnership., 2008, Consultation: Lancashire Climate Change Strategy $2008-2013,11$.

Milligan, J., O'Riordan, T., 2007, 'Governance for sustainable coastal futures', Coastal Management 35, 499-509.

Milligan, J., O'Riordan, T,. Nicholson-Cole ,S A, \& Watkinson, A R., 2008 'Nature conservation for future sustainable shorelines: Lessons from seeking to involve the public', Land Use Policy.

Porritt,J.,2008,'SNR/Prosperous,Places/NewBuild'.December22, http://www.jonathonporritt.com/pages/2008/12/snrprosperous placesnew build 1.htm 
Seixas, C.S., 2004, 'Barriers to local-level, participatory ecosystem assessment and management in Brazil', Millennium Ecosystem Assessment Conference, Alexandria, March 17-20.

UK Cabinet Office., 2010, The Coalition our Programme for Government, May, Ref: 401238 / 0510 http://www.cabinetoffice.gov.uk/media/409088/pfg coalition.pdf

UK Prime Minister's Office., 2010a, 'Queen's Speech - Decentralisation and Localism Bill,' NumberTen.Gov.UK, May 25,

http://www.number10.gov.uk/queens-speech/2010/05/queens-speech-decentralisation-andlocalism-bill-50673

UK Prime Minister's Office., 2010b, ‘Queen's Speech - Energy Security and Green Economy Bill,' NumberTen.Gov.UK, May 25, http://www.number10.gov.uk/queensspeech/2010/05/queens-speech-energy-security-and-green-economy-bill-50650

UNECE., 1998, Convention on Access to information Pubic Participation in Decision Making and Access to Justice in Environmental Matters, Aarhus, Denmark, on 25 June 1998 http://www.unece.org/env/pp/documents/cep43e.pdf

UNECE., 2003 Progress Report on Status of Ratification and Implementation of the Aarhus Convention, Fifth Ministerial Conference, Environment for Europe Kiev, Ukraine 21-23 May

http://www.unece.org/env/documents/2003/pp/mp pp 20032 e.pdf 